\title{
Transmission of Podisus maculiventris tremulatory signals through plants
}

Research Article

\author{
Andrej Čokl ${ }^{1 *}$, Alenka Žunič ${ }^{1}$, Jocelyn G. Millar² \\ ${ }^{1}$ Department of Entomology, National Institute of Biology, \\ 1000 Ljubljana, Slovenia \\ ${ }^{2}$ Department of Entomology, University of California, \\ Riverside, CA 92521, U.S.A.
}

Received 17 July 2009; Accepted 02 September 2009

Abstract: Males of the predaceous stink bug Podisus maculiventris (Say) (Heteroptera: Pentatomidae: Asopinae) emit low frequency tremulatory signals. Laser vibrometry was used to record and analyze naturally emitted signals, focusing on variation in signal velocity and frequency during transmission through plants (Phaseolus vulgaris L. and Plumbago auriculata Lam.) as a function of distance from the vibrational source. Signal velocity varied individually between 2 and $15 \mathrm{~mm} / \mathrm{s}$ recorded on a plant close to the calling male and decreased by 0.3 to $1.5 \mathrm{~dB} / \mathrm{cm}$ on bean and 0.3 to $0.9 \mathrm{~dB} / \mathrm{cm}$ on plumbago. The dominant frequency of signals was variable at frequencies below $50 \mathrm{~Hz}$. On bean frequencies centered around $10 \mathrm{~Hz}$ or $20 \mathrm{~Hz}$ were dominant for signals recorded at the source. Transmission through bean resulted in an increase in the $20 \mathrm{~Hz}$ peak relative to other frequencies in the signal. Variation of the dominant frequencies of signals transmitted through plumbago stems were more predictable, showing typical changes in amplitude relative to the distance from the source. The regular variation of the dominant frequency along the stem with linear increase of signal velocity at decreasing distance from the source may provide plant-dwelling insects with information about the distance to the calling individual.

Keywords: Pentatomidae • Podisus maculiventris • tremulation • Transmission • Plant • Velocity • Frequency • Distance (c) Versita Warsaw and Springer-Verlag Berlin Heidelberg.

\section{Introduction}

Predatory stink bugs (Pentatomidae: Asopinae) with their carnivorous feeding habits are widely used as biological control agents for control of insect pests [1]. Although it was demonstrated more than a decade ago that plant substrates represent an important medium for information exchange in the asopine species Podisus maculiventris (Say) [2], information about substrateborne sound communication by predaceous stink bugs was lacking until 2006, when Gogala [3] first recorded vibratory signals of Picromerus bidens L. Recently, Shestakov [4] recorded the vibratory signals of four asopine species, $P$. bidens, Troilus luridus F., Zicrona caerulea L., and Arma custos F. Substrate-borne sound communication has been described in detail for $P$. maculiventris [5], with signals produced by abdomen vibration, tremulation, and percussion. The song repertoire of this species covers a wide spectral range, from low frequency tremulatory signals of a few $\mathrm{Hz}$, to broad-band percussion signals with several frequency components between 1 and $3 \mathrm{kHz}$. Tremulatory signals were first reported in the Heteroptera in Pyrrhocoris apterus L. (Heteroptera, Pyrrhocoridae) by Benediktov [6], and Žunič et al. [5] demonstrated that the tremulatory signals of $P$. maculiventris males are an essential component of mating behavior. The mean dominant frequency of these signals varied between 8 and $22 \mathrm{~Hz}$, recorded either on a non-resonant substrate or on a plant. The dispersive nature of bending waves, standing wave conditions [7], and the low-pass filtering properties of green plants [8] all result in significant changes in the amplitude, temporal, and frequency parameters of transmitted vibratory signals. Broad-band stridulatory 

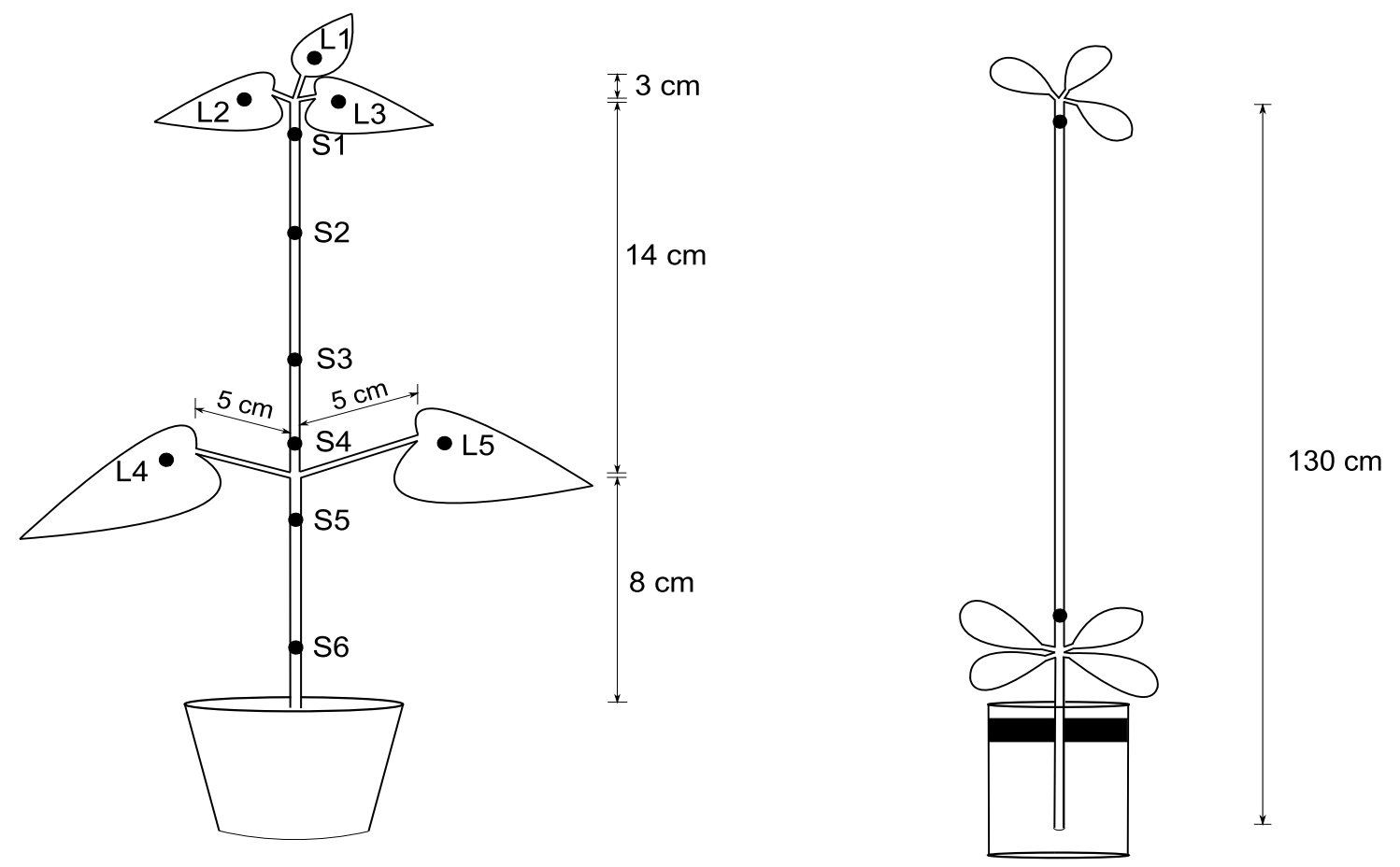

Figure 1. Schematic drawing of the bean (left) and plumbago (right) test plants. All recording points are shown for bean and just the upper- and lowermost ones for plumbago.

signals with dominant frequencies above $500 \mathrm{~Hz}[3]$ are strongly attenuated during transmission due to the lowpass filtering properties of green plants [9]. The narrowband signals of about $100 \mathrm{~Hz}$ produced by phytophagous stink bugs (Pentatomidae: Pentatominae) by vibration of the abdomen [10], are well tuned to the mechanical properties of the plant substrates through which they are usually transmitted [11], and consequently, the signals are transmitted efficiently over distances well above one meter along the green plant stem [8]. However, to our knowledge, the transmission of low frequency tremulatory signals through green plants, such as those produced by $P$. maculiventris, has not been studied.

Thus, the objective of the present study was to investigate the efficiency of communication with tremulatory signals through green plants, using P. maculiventris as a test organism, and green bean, Phaseolus vulgaris L., and plumbago, Plumbago auriculata Lam., as substrates. The study was conducted exclusively with naturally emitted signals, focusing on potential correlations between distance from the source and signal velocity and frequency parameters. We hypothesize that communication with spectrally different signals through plants is advantageous because it avoids "dead zones" at nodes of standing waves. We further hypothesize that tremulatory signals might provide information about distance to the signaler.

\section{Experimental Procedures}

\subsection{Animals and plants}

All experiments were conducted at the Department of Entomology, University of California, Riverside (U.S.A.) on laboratory-reared adult spined soldier bugs, P. maculiventris (at least 4 days after the final moult). The colony was started from eggs purchased from Rincon Vitova Insectaries, Ventura, CA. The bugs were reared on green beans, raw sunflower seeds, Helianthus annuus L., and larvae of either almond moth, Caudra cautella (Walker), beet armyworm, Spodoptera exigua (Hübner), or navel orangeworm, Amyelois transitella (Walker). Cylindrical cardboard containers $(15 \mathrm{~cm}$ diam $\times 6 \mathrm{~cm}$ in height) with individuals separated by sex were held at $26^{\circ} \mathrm{C}, 55 \% \mathrm{RH}$, and with a photophase of $16: 8$ $(L: D) h$ in an environmental chamber. Each experimental animal was used only once per day.

Naturally emitted signals were recorded from four green bean plants and from a cutting of plumbago, a woody shrub. Each bean plant was grown in a $10 \mathrm{~cm}$ diam. pot filled with vermiculite; the plant's morphology, dimensions, and recording points are shown in Figure 1. The plumbago stem was held in a glass jar $(7 \mathrm{~cm}$ diam. $\times 13 \mathrm{~cm}$ in height) filled with water. The stem was wrapped in foam to hold it in place, and to isolate it from 
the glass wall to reduce external vibratory noise. The stem was $130 \mathrm{~cm}$ long, with $24 \mathrm{~cm}$ in the water. All the leaves and side branches were pruned except for the 4 leaves at the bottom of the stem below the most distant measuring point, and the uppermost leaves $(2-4 \mathrm{~cm}$ in length and $1 \mathrm{~cm}$ broad). The stem diameter increased from $3 \mathrm{~mm}$ at the top to $5 \mathrm{~mm}$ at the bottom measuring point. The uppermost point was $3 \mathrm{~cm}$ below the stemleaves junction and the lowest $90 \mathrm{~cm}$ away.

\subsection{Recording of signals}

Experiments were conducted in an enclosed room from $0900-1600$ (3 - $10 \mathrm{~h}$ after the start of photophase) under an ambient mix of artificial and natural light conditions, and constant temperature $\left(23 \pm 1^{\circ} \mathrm{C}\right)$ and humidity. Signals were recorded with a portable digital laser vibrometer (PDV-100, Polytec GmbH, Waldbronn, Germany) from points on the plant (Figure 1) painted with white typewriter correction fluid on an area of less than $1 \mathrm{~mm}^{2}$ to obtain better reflection of the beam oriented perpendicular to the surface. Recorded signals (Figure 2) were digitized and stored via a sound card (24-bit, 96-kHz, 100 dB signal-to-noise ratio; Sound Blaster Extigy, Creative Laboratories Inc., Milpits, CA) on a laptop computer using Cool Edit Pro Version 2.0 software (Adobe Systems Inc. San Jose, CA). Signal velocity and frequency (FFT size 32.768, FFT overlap 75\%, smoothing window Blackman-Harris, slices displayed 1, dominant frequency and peak amplitude values determined by the program at $1 \mathrm{~Hz}$ and $1 \mathrm{~dB}$ precision) characteristics were determined by Sound Forge, Version 6.0 (Sonic Foundry Inc., Madison, WI) software. Velocity of the signal (as a vector quantity specifying time rate of change of displacement) was measured at the maximum amplitude of the pulse. For comparative purposes, frequency characteristics of tremulatory signals recorded on a loudspeaker membrane by Žunič and co-workers [5] were reinvestigated. Signals, recorded from a male and female signaling on a $10 \mathrm{~cm}$ diam. low-midrange loudspeaker (8 $\Omega$ impedance; RadioShack, Taipei, Taiwan) were digitized, stored, and analyzed as described above.

\subsection{Experiments on bean and plumbago}

A male and a female $P$. maculiventris were placed on the upper surface of the $P$. auriculata or $P$. vulgaris plant leaves. After a male started to emit tremulatory signals the female was removed. We define the reference leaf as the one from which a male was calling; in all cases (unless otherwise specified) the reference leaf was the one at the top of the bean or plumbago plant. Signal velocity was measured every $5 \mathrm{~cm}$ along the plumbago stem and compared with the reference value determined at the point near the calling male (distance
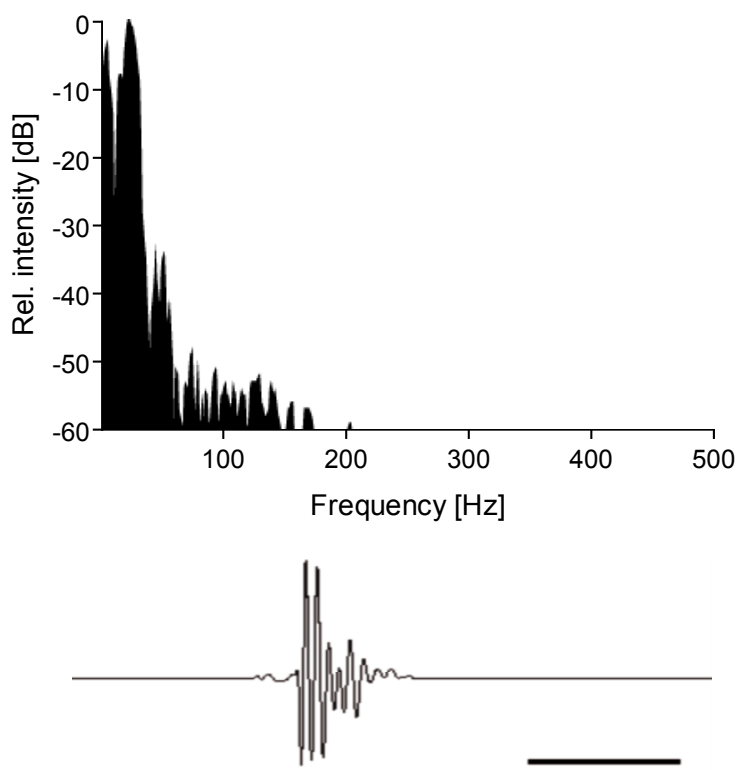

Figure 2. Frequency spectrum (above) and oscillogram with the $0.5 \mathrm{sec}$ time scale (below) of a $P$. maculiventris male tremulatory signal recorded on plumbago stem $11 \mathrm{~cm}$ from the male calling on a leaf

$<5 \mathrm{~cm}$ ). The relationship between signal velocity and dominant frequency with the distance from the source was determined only when reference velocity values measured at the beginning and at the end of the test did not differ significantly, as determined by the two-tailed Student's $t$-test.

\subsection{Statistics}

Two-tailed Student's $t$-tests, analysis of variance (ANOVA), Kruskal-Wallis and two sided Mann-Whitney U test for unpaired data were used for statistical analysis of data. Data from different individuals were averaged only for those whose mean values did not differ significantly. When inter-individual difference was significant the minimal and maximal mean values are shown.

\section{Results}

\subsection{Signal transmission through bean plants}

Naturally emitted tremulatory signals of 14 males were recorded on 4 different bean plants. The ranges of velocity and dominant frequency values were similar for all four plants. The velocity measured less than $5 \mathrm{~cm}$ from the source differed individually between $2.9 \pm 0.5$ $(n=6)$ and $13.7 \pm 1.2(n=9) \mathrm{mm} / \mathrm{s}$ for 11 males calling from the leaf and between $0.6 \pm 0.3(n=10)$ and $2.3 \pm 1.4(n=9)$ $\mathrm{mm} / \mathrm{s}$ for the remaining three males that tremulated on the stem. 


\begin{tabular}{|c|c|c|c|c|c|c|}
\hline & \multicolumn{2}{|c|}{$\begin{array}{l}\text { Low frequency peak } \\
\qquad(\mathrm{Hz})\end{array}$} & \multicolumn{2}{|c|}{$\begin{array}{l}\text { Middle frequency peak } \\
\qquad(\mathrm{Hz})\end{array}$} & \multicolumn{2}{|c|}{$\begin{array}{l}\text { High frequency peak } \\
\qquad(\mathrm{Hz})\end{array}$} \\
\hline Loudspeaker & \multicolumn{2}{|c|}{$\begin{array}{c}5.6 \pm 2.4 \\
(n=90, N=6)\end{array}$} & \multicolumn{2}{|c|}{$\begin{array}{c}18.0 \pm 3.5 \\
(n=78, N=6)\end{array}$} & \multicolumn{2}{|c|}{$\begin{array}{c}32.5 \pm 5.6 \\
(n=82, N=6)\end{array}$} \\
\hline Bean leaf & $\begin{array}{c}4.7 \pm 1.2 \\
(n=8)\end{array}$ & $\begin{array}{c}9.2 \pm 2.4 \\
(n=11)\end{array}$ & \multicolumn{2}{|c|}{$\begin{array}{c}20.2 \pm 3.2 \\
(n=47, N=6)\end{array}$} & $\begin{array}{c}27.8 \pm 0.5 \\
(n=4)\end{array}$ & $\begin{array}{c}32.0 \pm 0.5 \\
(n=7)\end{array}$ \\
\hline Bean stem & $\begin{array}{c}3.6 \pm 1.4 \\
(n=30)\end{array}$ & $\begin{array}{c}7.4 \pm 0.7 \\
(n=9)\end{array}$ & $\begin{array}{c}13.1 \pm 0.9 \\
(n=10)\end{array}$ & $\begin{array}{c}16.4 \pm 2.8 \\
(n=28)\end{array}$ & $\begin{array}{c}26.8 \pm 3.8 \\
(n=10)\end{array}$ & $\begin{array}{c}31.7 \pm 2.9 \\
(n=13)\end{array}$ \\
\hline \multirow[t]{2}{*}{ Plumbago stem } & $\begin{array}{c}2.8 \pm 0.4 \\
(n=6)\end{array}$ & $\begin{array}{c}4.7 \pm 0.5 \\
(n=7)\end{array}$ & & & & \\
\hline & $\begin{array}{c}8.0 \pm 0.0 \\
(n=3)\end{array}$ & $\begin{array}{c}13.3 \pm 2.9 \\
(n=6)\end{array}$ & $\begin{array}{c}17.3 \pm 1.5 \\
(n=19)\end{array}$ & $\begin{array}{c}21.3 \pm 1.3 \\
(n=7)\end{array}$ & $\begin{array}{c}24 \pm 0 \\
(n=3)\end{array}$ & $\begin{array}{c}30.5 \pm \\
0.6(n=4)\end{array}$ \\
\hline
\end{tabular}

Table 1. The mean values ( \pm SD) of dominant frequency peaks in $\mathrm{Hz}$ of tremulatory signals emitted and recorded on a loudspeaker membrane, or on bean or plumbago plants. Where individual mean values differed significantly (ANOVA, $P<0.05$ ) minimal and maximal values are shown.

Differences in the decrease in velocity of vibrations transmitted to the top or bottom of the plant were measured for signals emitted on the lower bean leaf. Signals transmitted to the top of the plant were significantly less attenuated than those transmitted to its base (2-sided Mann-Whitney $U$ test for unpaired data, $P<0.05)$; mean values of $3.3 \pm 0.5 \mathrm{~mm} / \mathrm{s}(\mathrm{n}=6)$ and $2.3 \pm 0.3 \mathrm{~mm} / \mathrm{s}(\mathrm{n}=6)$ were measured on the stem at $5 \mathrm{~cm}$ above and below the signaling bug respectively. The mean attenuation rate $(0.41 \pm 0.17 \mathrm{~dB} / \mathrm{cm}, \mathrm{n}=59)$ did not differ significantly when measured at most points on the same plant (Kruskal-Wallis test, $\mathrm{P}=0.4226, \mathrm{NS}$ ), with minimal amplitude at $9(0.32 \pm 0.21 \mathrm{~dB} / \mathrm{cm}, \mathrm{n}=6)$ and maximal amplitude at $20 \mathrm{~cm}(0.53 \pm 0.05 \mathrm{~dB} / \mathrm{cm}, \mathrm{n}=5)$ distance from the source. Significantly higher attenuation rates (2-sided Mann-Whitney $U$ test for unpaired data, $P<0.01$ ) were measured for signals recorded on one of the neighboring upper leaves $(1.54 \pm 0.23 \mathrm{~dB} / \mathrm{cm}, \mathrm{n}=6$, distance $=5 \mathrm{~cm})$ and on the stem base $25 \mathrm{~cm}$ from the source $(0.82 \pm 0.06 \mathrm{~mm} / \mathrm{s}, \mathrm{n}=6$, distance $=25 \mathrm{~cm})$.

Signals recorded on the non-resonant loudspeaker membrane or on plants had dominant frequencies below $50 \mathrm{~Hz}$. The mean frequency values of characteristic spectral peaks, determined as the low, middle, and high frequency components, are shown in Table 1 for signals recorded on the loudspeaker membrane, and on bean leaves or stem at a distance of less than $4 \mathrm{~cm}$ from the tremulating male. Each of these prominent peaks could be dominant. For the signals recorded from the loudspeaker $(n=100)$, the low frequency peak was dominant in $90 \%$ of the recorded signals, with the middle frequency being dominant in $9 \%$ and the high frequency in $1 \%$. For signals recorded from bugs tremulating on leaves $(n=206)$, the low frequency peak was dominant in $47 \%$ of the signals, whereas the high frequency peak was dominant in $31 \%$, and the middle frequency in $23 \%$. The middle frequency peak was dominant in the majority (64\%) of signals $(n=61, N=3)$ emitted from bugs tremulating on the stem.

During transmission from a reference leaf to other parts of the same plant (Plant 2) the ratio of the low, middle, or high frequency peaks changed (Table 2, Figure 3). The middle frequency peak was dominant in more than half of the signals from all tested points on the plant, whereas the percentage of low and high frequency dominant peaks decreased to less than 35 and $5 \%$ respectively.

\begin{tabular}{c|ccccc}
\hline & Distance & No. spectra & \% Low frequency & \% Middle frequency & \% High frequency \\
\hline \hline Reference & $<2 \mathrm{~cm}$ & 176 & 55.7 & 12.5 & 31.8 \\
Neighboring leaf & $>5 \mathrm{~cm}$ & 123 & 35.0 & 60.2 & 4.8 \\
& $<2 \mathrm{~cm}$ & 150 & 55.3 & 16.0 & 28.7 \\
Reference & $2-18 \mathrm{~cm}$ & 378 & 15.1 & 80.4 & 4.5 \\
Stem & $<2 \mathrm{~cm}$ & 66 & 63.6 & 16.7 & 19.7 \\
Reference & $26-30 \mathrm{~cm}$ & 102 & 35.3 & 63.7 & 1.0 \\
Distant leaf & & & & \\
\hline
\end{tabular}

Table 2. The relative numbers (\%) of the low, middle, or high frequency peaks as the dominant frequencies in spectra of signals recorded on the upper leaf (reference) and on the neighboring leaf, stem, or distant leaf. No.: the number of all analyzed signals. 



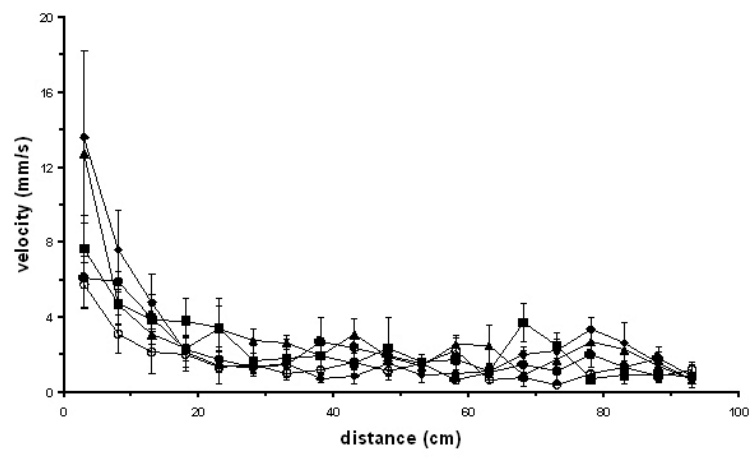

Figure 4. Mean ( \pm SD) velocity of tremulatory signals emitted by 4 male $P$. maculiventris from the top plumbago leaf and recorded on the stem at different distances from the source.

\subsection{Transmission through the plumbago stem} remulatory signal frequency and velocity variation with distance were measured for 7 males signaling from the same reference (top) leaf of the $P$. auriculata stem. The velocity of naturally emitted signals recorded on the stem $3 \mathrm{~cm}$ below the signaler varied for individuals between $5.8 \pm 1.2(n=10)$ and $13.6 \pm 4.6 \mathrm{~mm} / \mathrm{s}$ $(n=10)$. At the most distant measuring point

A

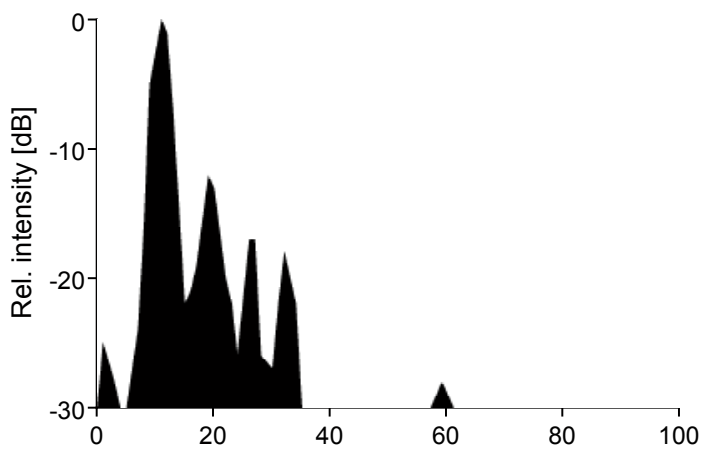

C

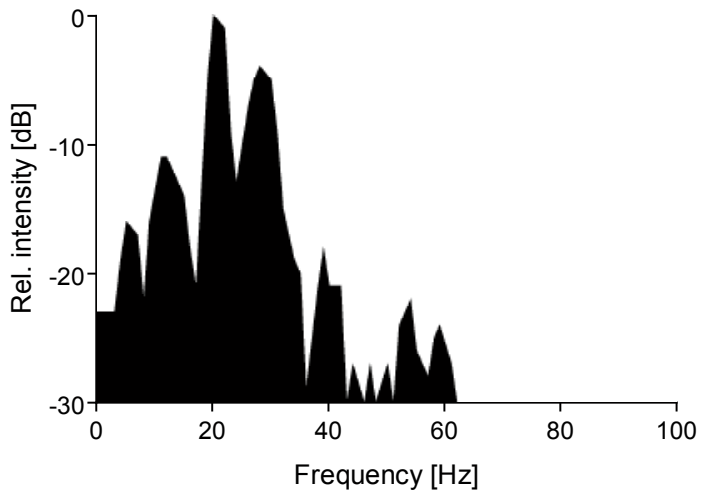

(93 $\mathrm{cm}$ from the source) the velocity decreased by 14 to $28 \mathrm{~dB}(0.2-0.3 \mathrm{~dB} / \mathrm{cm})$. The distance versus velocity curves of the seven males (Figure 4) for which tremulatory signals were recorded along the whole stem showed fast decreases of 6 to $16 \mathrm{~dB}$ within the first $18 \mathrm{~cm}(0.3-0.9$ $\mathrm{dB} / \mathrm{cm}$ ) and irregular variation of mean values around 2 $\mathrm{mm} / \mathrm{s}$ along the rest of the tested distance.

The tremulatory signals recorded from plumbago had similar spectral properties to those recorded from the loudspeaker or from bean plants (Table 1). Each of the four prominent peaks in the range below $50 \mathrm{~Hz}$ could be dominant (Figure 5). Signals emitted by the seven males showed characteristic distributions of dominant frequencies along the tested stem (Figure 6). The frequency peak around $10 \mathrm{~Hz}$ (Figure 5A) dominated along the upper $20 \mathrm{~cm}$ of the stem and at distances above $50 \mathrm{~cm}$. At distances between 20 and $50 \mathrm{~cm}$ from the source, the peak around $4 \mathrm{~Hz}$ (Figure 5B) was dominant together with the peak around $20 \mathrm{~Hz}$; the latter also was dominant ( 60\%) at distances above $60 \mathrm{~cm}$ (Figure $5 \mathrm{C}$ ). The peak around $28 \mathrm{~Hz}$ (Figure 5D) was dominant in rare cases and we could find no part of the stem where high frequency peaks would regularly prevail.

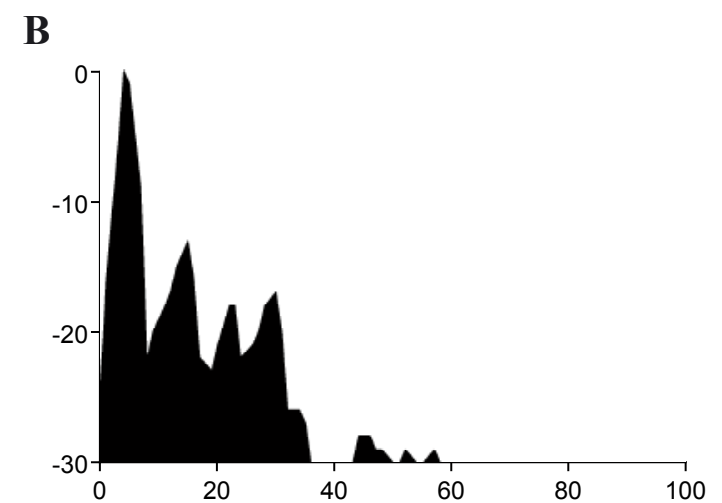

D

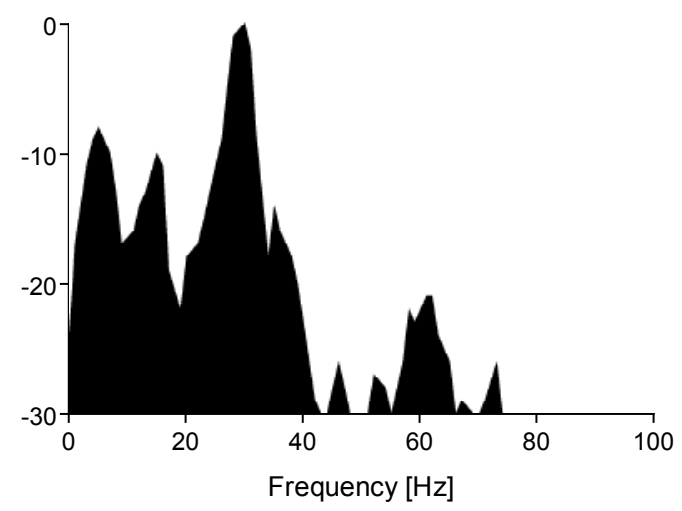

Figure 5. Frequency spectra of signals emitted by a male $P$. maculiventris from the plumbago top leaf and recorded on the stem at different distances from the source $(A-10 \mathrm{~cm}, B-30 \mathrm{~cm}, C-80 \mathrm{~cm}, D-10 \mathrm{~cm})$. 

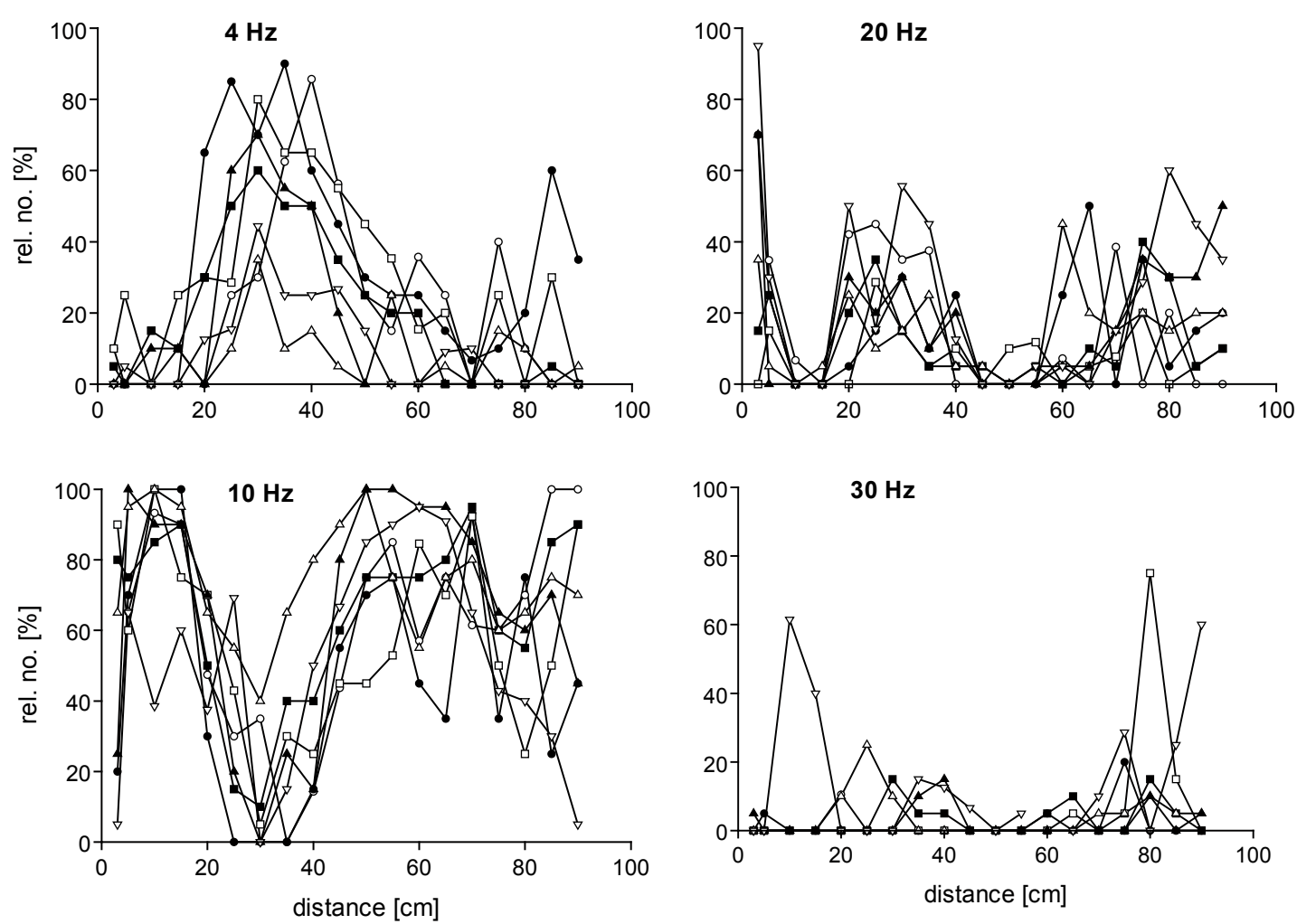

Figure 6. Relative numbers (\%) of the characteristic dominant frequency peaks $(4,10,20$ and $30 \mathrm{~Hz})$ of tremulatory signals emitted by 7 P. maculiventris males from a plumbago upper leaf and recorded on the stem at different distances from the source.

\section{Discussion}

Insects communicate through substrate, air or water $[12,13]$ by signals of different frequency characteristics produced by stridulation, percussion, vibration, or clicking mechanisms [14]. Because of their small body size and high damping of high frequency airborne sound in vegetation [15] most plant-dwelling species communicate through the substrate [13] with dispersive $[7,16]$ and non-dispersive [17] bending waves. The consequences of different physical properties of plant substrates for insect communication have been described [18], and McNett et al. [19] demonstrated that a point on a plant stem being vibrated by an insectproduced vibrational signal moves in an elliptical path when observed relative to a cross-sectional plane. The use of different sound producing mechanisms in Heteroptera [3,5] can be explained by various mechanical properties of plants through which they communicate $[18,20,21]$. Contrary to mate location and recognition $[10,22,23]$ to date it is not known whether insects can derive information from substrate-borne signals that will indicate the distance to the source. Such information may be provided by one or more signal parameters varying reproducibly with the distance. Because different frequencies are attenuated to different extents with distance from the signaler, signals that are composed of different frequencies may contain embedded information with regard to distance from the source. In this context, the very low frequency tremulatory signals of $P$. maculiventris [5], which extend the spectral range of the vibratory signals described from Heteroptera, may assist in the determination of distance between signaler and receiver.

Thus, the narrow-band vibratory signals of about $100 \mathrm{~Hz}$ that are produced by all species of the subfamily Pentatominae that have been examined to date [10], including $P$. maculiventris [5], are transmitted through green plants with low attenuation, and with echoes from plant roots and apexes that create standing wave conditions in stems and stalks. This results in regularly repeated points along the plant with minimal (nodes) and maximal (antinodes) amplitudes [8]. Thus, a receiver insect that is approaching a signaler and passing through nodes and antinodes for a particular frequency cannot rely on the change in signal amplitude to provide information about distance to the source. The percussion signals of $P$. maculiventris recorded on a non-resonant substrate 
are characterized by frequency components above $1 \mathrm{kHz}$ which almost completely disappear in the spectra of signals recorded at increasing distances from a signaler on a leaf [5]. As such, these signals are similar to those of Cydnidae, Scutelleridae, Miridae, and many other Pentatomorpha and Cimicomorpha land-dwelling bugs that produce stridulatory signals [3] whose amplitude is highly attenuated by the low pass filtering properties of green plants [9]. Thus, these signals might only transmit information about distance to the source over a few $\mathrm{cm}$.

The tremulatory signals of $P$. maculiventris are produced during courtship [5]. They may contain information about size or fitness, as shown for the katydid Conocephalus nigropleurum (Bruner) (Orthoptera: Tettigoniidae) [24] but this aspect has not yet been investigated. In the present study, we observed that tremulatory signals continued to be produced for several minutes after a female was removed from the plant, suggesting that a male might use these signals to attract other females on a plant. In this context, tremulatory signals should be transmitted over longer distances, and they might also carry information about distance to the source. In fact, our results showed that the velocity of $P$. maculiventris tremulatory signals decreased linearly up to $20 \mathrm{~cm}$ from the source, and at a faster rate than signals produced by abdominal vibrations. This linear increase of signal amplitude with decreasing distance may allow efficient distance discrimination on the stem over distances up to $20 \mathrm{~cm}$. At distances above $20 \mathrm{~cm}$, the velocity varies irregularly around a central value, with an attenuation rate too low to provide information about distance to the signaler. Although the signal velocity decreases sharply at $\sim 20 \mathrm{~cm}$ from the signaler, its initial value is sufficient to keep it above the expected receptor threshold detection level $\left(10^{-4}-10^{-5} \mathrm{~m} / \mathrm{s}\right)$ [25] at distances well above $1 \mathrm{~m}$ from the source. Over these longer distances, the regular distribution of different dominant peaks along the stem may provide further information about distance to the signaler. That is, at least under our experimental conditions, the variation of the dominant frequency with distance for the signal components of approximately 10 and $4 \mathrm{~Hz}$ respectively, may guide a receiver to distances at which the signal components whose velocity increases linearly with decreasing distance can provide shorter range distance estimation.

Thus, we suggest that more attention should be paid to the largely overlooked and poorly studied low frequency vibrations produced by insects during reproductive behaviors. Contrary to the known role of vibratory signals in mate location and recognition [22,23], and to the extensively studied vibrational directionality of plant-dwelling insects [26], to date there has been no experimental evidence to suggest that distance information might be encoded in vibrational signals. Furthermore, although it is likely that Heteroptera that use vibrational signals have vibration sensing systems analogous to those described for $N$. viridula $[25,27]$ there is a gap in our knowledge with regard to the response of heteropteran vibrational receptors to stimuli below $30 \mathrm{~Hz}$. Their phase coupled response patterns and thresholds about $20 \mathrm{~dB}$ below the velocity of tremulatory signals recorded on a plant make campaniform sensilla and/or the chordotonal organs located in joints [25] the most obvious candidates to be involved in detection of such low frequency vibrations, but we cannot exclude the possibility that under specific conditions other mechanoreceptors may be involved. For example, vibration sensitive sensilla described in Cupiennius salei Keys. (Arachnida: Ctenidae) form a ventral bridge over the metatarsus-tarsus joint, and are optimally tuned to leg vibrations with frequencies of 70 and 150 $\mathrm{Hz}$ [28]. The trichobotria of the same species are tuned to frequencies between 40 and $600 \mathrm{~Hz}$, and the range of optimal frequencies shifts towards lower values with increasing length [28]. Furthermore, leaf vibrations induce air movements in their immediate surroundings with a temporal pattern that follows that of substrateborne signals [29]. Thus, the Johnston's organ that measures air movements [30] or even the leg itself [31] are potentially sensitive enough to detect the airborne components of the tremulatory signals described here.

We conclude that the tremulatory signals recorded from male $P$. maculiventris enlarge the frequency window through which this species communicates. Signals with different spectral characteristics are designed and optimized for different functions, and to operate over different distances between signaler and receiver. To confirm the informational value of tremulatory signals comparative investigations with other types of bugs are needed together with studies of anatomy and function of receptors sensitive to frequencies below $30 \mathrm{~Hz}$.

\section{Acknowledgements}

We are grateful to Mariana Krugner and J. Steven McElfresh for rearing $P$. maculiventris, and to Jernej Polajnar for preparation of figures. The authors wish to thank both referees for their comments on the manuscript. The work was financed by the Slovenian Research Agency (Program P1-0255-0105, project J12133-0105) and by Hatch project CA-R*ENT-5181-H to JGM. 
[1] De Clercq P., Predaceous stinkbugs (Pentatomidae: Asopinae), In: Schaefer C.W., Panizzi A.R., (Eds.), Heteroptera of Economic Importance, Boca Raton London New York Washington D.C., CRC Press, 2000

[2] Pfannenstiel R.S., Hunt R.E., Yeargan K.V., Orientation of hemipteran predator to vibrations produced by feeding caterpillars, J. Insect Behav., 1995, 8, 1-9

[3] Gogala M., Vibratory signals produced by Heteroptera - Pentatomorpha and Cimicomorpha, In: Drosopoulos S., Claridge M.F., (Eds.), Insect Sound and Communication: Physiology, Behavior, Ecology and Evolution, Boca Raton London New York, CRC Taylor \& Francis Group, 2006

[4] Shestakov L.S., Studies of vibratory signals in pentatomid bugs (Heteroptera, Asopinae) from European Russia, Entomol. Rev., 2008, 88, 20-25

[5] Žunič A., Čokl A., Virant-Doberlet M., Millar J.G., Communication with signals produced by abdominal vibration, tremulation, and percussion in Podisus maculiventris (Heteroptera: Pentatomidae), Ann. Entomol. Soc. Am., 2008, 101, 1169-1178

[6] Benediktov A.A., Tremulation of firebugs Pyrrhocoris apterus L. (Heteroptera, Pyrrhocoridae), Moscow Univ. Biol. Sci. Bull., 2007, 62, 186-187

[7] Michelsen A., Fink F., Gogala M., Traue D., Plants as transmission channels for insect vibrational songs, Behav. Ecol. Sociobiol., 1982, 11, 269-281

[8] Čokl A., Zorović M., Millar J.G., Vibrational communication along plants by the stink bugs Nezara viridula and Murgantia histrionica, Behav. Processes, 2007, 75, 40-54

[9] Čokl A., Nardi C., Bento J.M.S., Hirose E., Panizzi A.R., Transmission of stridulatory signals of the burrower bugs, Scaptocoris castanea and Scaptocoris carvalhoi (Heteroptera: Cydnidae) through the soil and soybean, Physiol. Entomol., 2006, 31, 371-381

[10] Čokl A., Stink bug interaction with host plants during communication, J. Insect Physiol., 2008, 54, 1113-1124

[11] Čokl A., Zorović M., Žunič A., Virant-Doberlet M., Tuning of host plants with vibratory songs of Nezara viridula L. (Heteroptera: Pentatomidae), J. Exp. Biol., 2005, 208, 1481-1488

[12] Cocroft R.B., Rodriguez R.L., The behavioral ecology of insect vibrational communication, Bioscience, 2005, 55, 323-334
[13] Greenfield M.D., Signalers and Receivers: Mechanisms and Evolution of Arthropod Communication, New York, Oxford University Press, 2002

[14] Ewing A.W., Mechanisms of Sound Production, In: Ewing A.W., (Ed.), Arthropod Bioacoustics, Edinburgh, Edinburgh University Press, 1989

[15] Markl H., Vibrational Communication, In: Huber F., Markl H., (Eds.), Neuroethology and Behavioral Physiology: Roots and Growing Points, Berlin Heidelberg New York Tokyo, Springer Berlag, 1983

[16] Cremer L., Heckl M., Petersson B.A.T., Structureborne sound: structural vibrations and sound radiation at audio frequencies, Berlin, Springer, 2005

[17] Casas J., Magal C., Sueur J., Dispersive and nondispersive waves through plants: implications for arthropod vibratory communication, Proc. Roy. Soc. B., 2007, 274, 1087-1092

[18] Cocroft R.B., Shugart K.T., Konrad K.T., Tibbs K., Variation of plant substrates and its consequences for insect vibrational communication, Ethology, 2006, 112, 779-789

[19] McNett G.D., Miles R.N., Homentcovschi D., Cocroft R.B., A method for two-dimensional characterization of animal vibrational signals transmitted along plant stems, J. Comp. Physiol. A., 2006, 192, 1245-1251

[20] Elias D.O., Mason A.C., Hoy R.R., The effect of substrate on the efficacy of seismic courtship signal transmission in the jumping spider Habronattus dossenus (Aranea: Salticidae), J. Exp. Biol., 2004, 207, 4105-4110

[21] Henry C.S., Acoustic communication in neuropterid insects, In: Drosopoulos S., Claridge M.F., (Eds.), Insect Sound and Communication: Physiology, Behavior, Ecology and Evolution, Boca Raton London New York, CRC Taylor \& Francis Group, 2006

[22] Čokl A., Virant-Doberlet M., Communication with substrate-borne signals in small plant-dwelling insects, Annu. Rev. Entomol., 2003, 48, 29-50

[23] Virant-DoberletM., ČokIA., Vibrationalcommunication in insects, Neotrop. Entomol., 2004, 33, 121-134

[24] De Luca P.A., Morris G.K., Courtship communication in meadow katydids: female preference for large male vibrations, Behaviour, 1998, 135, 777-793

[25] Čokl A., Functional properties of vibroreceptors in the legs of Nezara viridula (L.) (Heteroptera, Pentatomidae), J. Comp. Physiol., 1983, 150, 261269 
[26] Virant-Doberlet M., Čokl A., Zorović M., Use of substrate vibrations for orientation: from behaviour to physiology, In: Drosopoulos S., Claridge M.F., (Eds.), Insect Sound and Communication: Physiology, Behavior, Ecology and Evolution, Boca Raton London New York, CRC Taylor \& Francis Group, 2006

[27] Čokl A., Doberlet-Virant M., Zorović M., Sense organs involved in the vibratory communication of bugs, In: Drosopoulos S., Claridge M.F., (Eds.), Insect Sound and Communication: Physiology, Behavior, Ecology and Evolution, Boca Raton London New York, CRC Taylor \& Francis Group, 2006
[28] Barth F.G., A Spider's World: Senses and behavior, Berlin, Heidelberg, Springer-Verlag, 2002

[29] Casas J., Bacher S., Tautz J., Meyhöfer R., Pierre D., Leaf vibrations and air movements in a leafminerparasitoid system, Biol. Control, 1998, 11, 147-153

[30] Kirchner W.H., Hearing in honeybees: the mechanical response of the bee's antenna to near field sound, J. Comp. Physiol. A, 1994, 175, 261265

[31] Shaw S.R., Detection of airborne sound by a cockroach "vibration detector". A possible missing link in insect auditory evolution, J. Exp. Biol., 1994, 193, 13-47 